\title{
Evaluating Factors Associated with the Use of Aphrodisiacs among Adult Male Residents in Ashaiman Municipality, Ghana
}

\author{
Stephen Manortey*, Portia Afi Mensah, Gideon Kwarteng Acheampong \\ Ensign College of Public Health, Kpong, Ghana \\ Email: *steve.manortey@ensign.edu.gh
}

How to cite this paper: Manortey, S., Mensah, P.A. and Acheampong, G.K. (2018) Evaluating Factors Associated with the Use of Aphrodisiacs among Adult Male Residents in Ashaiman Municipality, Ghana. Open Access Library Journal, 5: e4876.

https://doi.org/10.4236/oalib.1104876

Received: August 31, 2018

Accepted: September 25, 2018

Published: September 28, 2018

Copyright $\odot 2018$ by authors and Open Access Library Inc.

This work is licensed under the Creative Commons Attribution International License (CC BY 4.0).

http://creativecommons.org/licenses/by/4.0/

\begin{abstract}
Background: There is limited scientific evidence supporting the efficacy of aphrodisiacs and more worrying is the fact that potential adverse health effects could result from the abuse of aphrodisiacs. Despite the safety concerns raised by the FDA on the abuse of unregistered sex enhancing products, the patronage remains high amidst debilitating side effects. We explore the factors influencing the use of aphrodisiacs while assessing the prevalence of aphrodisiac usage among men in the Ashaiman Municipality of Greater Accra Region, Ghana. Methods: A cross-sectional study was carried out between January and March 2018 at the Ashaiman Municipality. Structured questionnaires were administered to 370 consented and purposively selected adult males (18 years and above) through interviews. Data on variables such as respondent's socio-demographic characteristics, sexual characteristics, knowledge and use of aphrodisiacs were obtained. Analysis was done with aphrodisiac use as the main outcome of interest. A bivariate statistical analysis was done with aphrodisiac use as the main outcome of interest. Results: Out of the 352 men, 52.6\% reported ever using aphrodisiacs at some points in their lives. Majority (68.7\%) of the users first used aphrodisiacs between the ages of 18 and 25 years. Usage was found to be higher among those with lower educational attainment. Number of sexual partners, the presence of sexual problems, advertisement, and knowledge of side effects were statistically associated with the use of aphrodisiac $(\mathrm{p}<0.05)$. About $50 \%$ of the aphrodisiac users had no sexual problems indicating recreational use. Majority of the responders (52.4\%) acquired the aphrodisiacs from drug peddlers. Conclusions: This study revealed the use of aphrodisiac is still high among adult males, and that the participants' levels of education and knowledge of side effects serve as a protective factor to the likelihood of using aphrodisiacs. There is a need for health institutions to embark on extensive educational pro-
\end{abstract}


grammes to educate the public on the devastating health consequences from the indiscriminate use of aphrodisiacs without medical indication.

\section{Subject Areas}

Public Health

\section{Keywords}

Aphrodisiacs, Sexual Enhancement, Sexual Dysfunction, Ashaiman, Ghana

\section{Introduction}

Men and women throughout history have continually pursued various means to enhance, maintain and bring back their sexual ability or stimulate their sexual desire for the opposite sex. Sexual function and health is an essential component of life [1], hence the search for a remedy that can enhance sexual function has been an obsession. Reports from the United States (US) National Health and Social Life Survey approximates that $31 \%$ of men suffer from a sexual dysfunction in their lifetime [2]. This is an important public health problem that occurs in $10 \%-52 \%$ of men and $25 \%-63 \%$ of women globally [3]. The use of aphrodisiacs (sexual enhancers) has been the most common method to achieve this satisfaction [4]. An aphrodisiac is defined as a substance (food or drug) that arouses the sexual instinct, induces venereal desire and increases sexual pleasure and performance. Aphrodisiacs can be categorized into three types by their mode of action: libido increasing, sexual pleasure increasing and potency increasing [5]. Aphrodisiacs in recent years have become popular with the increased prevalence of sexual problems worldwide and the incidence of the problem is predicted to rise over 320 million in 2025 globally [6]. In Ghana, a similar trend has been observed along with an associated side effect, as the Ghana Public Health Association in 2016 indicated that, the increasing use of aphrodisiac is causing a lot of harm among many Ghanaians [7]. A study by Amidu et al., (2010), on the prevalence of male sexual dysfunction among the Ghanaian populace, revealed that sexual dysfunction affects $66 \%$ of Ghanaian men who are sexually active [8]. Again, similar findings from epidemiological studies indicate that sexual dysfunction increases with age and at least one complaint of sexual function is observed in a third of the elderly population [9]. Danquah et al., (2011), on the indiscriminate use of sex enhancing products among Ghanaians, revealed that most people overly patronize unregistered sex enhancers that have flooded the cities. Findings from their studies indicated that $61 \%$ of the male respondents were using sex enhancing products. In connection with the use of aphrodisiacs, another study on the consumption of alcoholic beverages mixed with aphrodisiacs showed that most Ghanaians consume alcoholic beverages mixed with aphrodisiacs [10]. Amidu et al., (2010), indicated that many Ghanaian men who purchase sex-enhancing medications do not actually need them 
as about $75 \%$ Ghanaians perceive an intravaginal ejaculatory latency of 7 - 25 min as being normal which is far above the $3-7$ minutes sex therapist indicates as being adequate [8]. According to Atindanbila et al., 2014, both natural (mostly herbal) and chemical aphrodisiacs are used by men of all ages and status in Ghana. However, findings from their studies showed that majority of the Ghanaian men use herbal (natural) aphrodisiacs [11]. This agrees with a report from the World Health Organization (WHO) showing that in developing countries at least $80 \%$ of the population depend on traditional medicines for their primary health care [12]. In 2015, the Ghana Food and Drug Authority (FDA) served a notice placing a ban on six (6) aphrodisiacs (herbal medicine) for men. The products were found to be adulterated with synthetic pharmaceutical ingredient Vardenafil, which is used in the preparation of prescription-only medicine for the management and treatment of erectile dysfunction. According to the FDA, adulteration of these products could result in kidney failure, problems with sight and hearing, other serious health implications such as heart attack, cerebrovascular hemorrhage leading to stroke, sudden cardiac death and sustained erection resulting in impotence [13]. Despite the safety concerns raised by the FDA on the abuse of unregistered sex enhancing products, the patronage remains high amidst debilitating side effects. Here, we assess the factors influencing the increasing use of aphrodisiacs among men in the Ashaiman Municipality in the Greater Accra Region of Ghana while determining the prevalence, "help-seeking" behaviours and the knowledge of effects from the use of aphrodisiacs among men

\section{Methods}

\subsection{Study Site}

The study was conducted in the Ashaiman Municipal, which lies within the south-eastern part of Ghana and is one of the municipalities within the Greater Accra Region. Ashaiman, the capital of the municipality is a vibrant commercial city and densely populated where both day and night life is very active. Ashaiman used to be a sub-district under the Tema Metropolitan Health Directorate, however, it was carved out of Tema as a Municipal in July 2008. The municipality is about $30 \mathrm{~km}$ away from Accra, the administrative capital city of Ghana, and spans over a land size of $45 \mathrm{~km}^{2}$. Currently, Ashaiman is the $5^{\text {th }}$ densely populated city in Ghana and the fastest growing urban city in the country. The 2010 Population and Housing Census shows the total population of the municipality is 190,972 with males constituting $49.1 \%$ and females $50.9 \%$ [14]. Presently, the municipality is divided into seven (7) sub-municipalities for the purposes of planning and delivery of health services.

\subsection{Study Method and Design}

A cross-sectional study was employed to collect data from selected sub-municipals (Tsinaiagber, Amui Jor, Blakpatsona) in the Ashaiman Municipality. Males above 18 years were sampled using a multi-stage sampling technique and included in 
the study. A questionnaire was used as the principal data collection instrument, information on the study subjects regarding their demographic characteristics, benefits derived from use of aphrodisiacs, the role of advertisements in the use of aphrodisiacs, help-seeking behaviour for sexual problems, knowledge level of health complications and other factors influencing the use of aphrodisiacs were obtained through interviews.

\subsection{Study Variables}

The utilization of aphrodisiacs was the dependent variable used in the logistic regression analysis in this study. The following were the explanatory variables explored;

1) Demographic characteristics such as; age, educational level, marital status, ethnicity, religion, level of education and occupation.

2) Prevalence of aphrodisiac usage. This captured previous usage and current usage of aphrodisiacs as well as the various types of aphrodisiacs used (whether herbal or orthodox). The sources of information and sources of acquisition for these aphrodisiacs were also included in the analysis because they were perceived to play an essential role in the use of aphrodisiac.

3) Reasons for use of aphrodisiacs. This took into consideration the proportion using aphrodisiac for medical reasons and those using it for recreational purposes. Recreational use was analyzed as the proportion using aphrodisiacs to gratify sexual partners, for prolonged sexual intercourse, for pleasure, insecurity, as a result of influence from friends and advertisements in the media. The relationship between help-seeking behaviours for sexual problems and use of aphrodisiacs was also explored.

4) Knowledge and perceptions of effects. Awareness of side effects from the use of aphrodisiacs was considered an important determinant and various health complications captured were headaches, fast heartbeat, sustained erection, impotence, heart attack, kidney failure and sudden death.

The target sample size was determined based on the reported usage prevalence of about $61 \%$ from an earlier study conducted among selected men in Ghana [15]. The estimated sample size was then calculated to be 366 with an anticipated $5 \%$ margin of error and a $95 \%$ confidence interval. The sample size was calculated using the formula;

$$
n=\frac{Z^{2} p(1-p)}{e^{2}}=\frac{1.96^{2} \times 0.61 \times 0.39}{0.05^{2}}=366
$$

where, $n=$ the required sample size, $p=$ prevalence of aphrodisiac usage, $Z=$ score at $95 \%$ confidence level, and $e=$ margin of error. The sample size was then rounded up to the nearest ten, bringing the total required sample size to 370 study participants.

\subsection{Data Management and Analysis}

All analyses were done using STATA statistical software package (StataCorp. 
2007. Stata Statistical Software. Release 14. StataCorp LP, College Station, TX, USA). Descriptive analysis of the various socio-demographic characteristics was done to generate percentages, frequencies, means, etc. Bivariate and multivariate logistic regression analyses were used to tease out potential association among selected socio-demographic characteristics and predict factors that statistically influence the use of aphrodisiacs at a predetermined significance level $(\alpha)$ less than 0.05 .

\subsection{Ethical Consideration}

Ethical and administrative approvals were obtained from the Ensign College of Public Health, Ethics Review Board. Permission was also sought from the Ashaiman Municipal Health Directorate and local authorities in the three sub-municipals. Participants were selected based on their willingness to partake in the study and signed individual informed consent was sought from each participant before enrolment into the study. As the consumption of aphrodisiacs is usually considered private and confidential, participants were assured of their anonymity and therefore no names were written on the questionnaires. Study subjects who were identified to be using aphrodisiacs detrimental to their health were referred for counselling at pre-identified health facilities.

\section{Results}

Out of the 370 respondents, 352 actively responded to the survey, generating a $95 \%$ response rate. The ages of the respondents ranged from 18 to 70 years with a mean age of $29.3 \pm 7.9$ years. While $34.1 \%$ of the respondents were married, $11.1 \%$ were co-habiting and $4 \%$ were divorced. Majority $(50.8 \%)$, reported being single at the time of the study. Sixty-nine percent of the respondents professed faith in Christianity, 21.6\% were Moslems and 9.3\% belonged to other religious faiths. Majority of the respondents were of the Ewes and Akans ethnic backgrounds.

Many of the respondents reported some level of formal education with only $14.5 \%$ having no formal education. The employment status of the participants showed that $16 \%$ of the respondents were unemployed whilst the rest were either artisans, drivers, civil servants (Table 1 ).

The results from the study showed that almost all the respondents 337 (95.7\%) had some knowledge of aphrodisiacs. About a half 185 (53\%), reported ever using aphrodisiacs, with 78 (42\%) out of the 185 being one time users whilst the rest currently use aphrodisiacs. On the question regarding the form of aphrodisiac ever used, $42.2 \%$ admitted having used an orthodox form of aphrodisiac, 15.1\% used herbal aphrodisiacs, 24.3\% used herbal with alcohol base ("bitters"), and the remaining reportedly used aphrodisiacs that came in form of sprays or creams. Of the 185 users, only 3.2\% were using aphrodisiacs based on recommendation by a health professional, $69.2 \%$ indicated recommendation was by friends and family, $17.8 \%$ by sexual partners and $9.6 \%$ used them based on 
Table 1. Socio-demographic characteristics of the study population.

\begin{tabular}{|c|c|}
\hline Variable $(\mathrm{N}=352)$ & $\mathrm{n}(\%)$ \\
\hline \multicolumn{2}{|l|}{ Age group (years) } \\
\hline $18-25$ & $121(34.38)$ \\
\hline $26-35$ & $168(47.73)$ \\
\hline $36-45$ & $52(14.77)$ \\
\hline $46-70$ & $11(3.13)$ \\
\hline \multicolumn{2}{|l|}{ Marital Status } \\
\hline Single & $179(50.85)$ \\
\hline Co-habiting & $39(11.08)$ \\
\hline Married & $120(34.09)$ \\
\hline Divorced & $14(3.98)$ \\
\hline \multicolumn{2}{|l|}{ Religion } \\
\hline Christianity & $243(69.03)$ \\
\hline Islamic & $76(21.59)$ \\
\hline Traditionalist & $33(9.38)$ \\
\hline \multicolumn{2}{|l|}{ Ethnicity } \\
\hline Akan & $98(27.84)$ \\
\hline Ewe & $101(28.69)$ \\
\hline $\mathrm{Ga}$ & $59(16.76)$ \\
\hline Hausa & $64(18.18)$ \\
\hline Others & $30(8.52)$ \\
\hline \multicolumn{2}{|l|}{ Educational Level } \\
\hline No Education & $52(14.49)$ \\
\hline Primary/JHS & $71(20.17)$ \\
\hline SHS/Tech/Voc. & $126(35.80)$ \\
\hline Tertiary & $104(29.55)$ \\
\hline \multicolumn{2}{|l|}{ Occupation } \\
\hline Artisan & $65(18.47)$ \\
\hline Civil Servant & $53(15.06)$ \\
\hline Petty Trader & $69(19.60)$ \\
\hline Driver & $36(10.23)$ \\
\hline Others & $73(20.74)$ \\
\hline Unemployed & $56(15.91)$ \\
\hline
\end{tabular}

recommendation from the media. Regarding the benefits derived from usage, about half (52.4\%) reported prolonged sexual intercourse as a positive outcome from usage, followed by improved performance (18.9\%), the gratification of sexual partner (15.1\%) and $13.5 \%$ reporting enhanced erection. When asked about any known side effect from usage, 58.9\% of the aphrodisiac users indicated the experienced effects of severe headache, general weakness and sustained erection from the use of aphrodisiacs (Table 2).

A bivariate analysis (Table 3 ) to test the association of selected socio-demographic characteristics with the use of aphrodisiacs showed that, the age of an individual, marital status, religion, occupation and educational level were statistically significant. The number of reported sex partners, claims of a sexual problem and the respondents' expectation of being queried on their sexual health by a care provider were found to be significantly associated with the use of aphrodisiacs. 
Table 2. Univariate analysis of respondents' knowledge and use of aphrodisiacs.

\begin{tabular}{|c|c|}
\hline Variable $(\mathrm{N}=352)$ & $\mathrm{n}(\%)$ \\
\hline \multicolumn{2}{|l|}{ Knowledge of aphrodisiacs } \\
\hline No & $15(4.26)$ \\
\hline Yes & $337(95.74)$ \\
\hline \multicolumn{2}{|l|}{ Ever Used aphrodisiacs } \\
\hline No & $167(47.44)$ \\
\hline Yes & $185(52.56)$ \\
\hline \multicolumn{2}{|c|}{ Among only those reporting ever used $(N=185)$} \\
\hline \multicolumn{2}{|l|}{ Age (years) at first use } \\
\hline $18-25$ & $127(68.65)$ \\
\hline $26-35$ & $51(27.57)$ \\
\hline $36-40$ & $7(3.78)$ \\
\hline \multicolumn{2}{|l|}{ Current use of aphrodisiac } \\
\hline Yes & $107(57.84)$ \\
\hline No & $78(42.16)$ \\
\hline \multicolumn{2}{|l|}{ Type being used } \\
\hline Orthodox capsule/pill & $78(42.16)$ \\
\hline Herbal & $28(15.14)$ \\
\hline Herbal with an alcohol base & $45(24.32)$ \\
\hline Cream/Spray & $34(18.38)$ \\
\hline \multicolumn{2}{|l|}{ Who recommended use } \\
\hline Friends/Family & $128(69.19)$ \\
\hline Media & $18(9.73)$ \\
\hline Health professional & $6(3.24)$ \\
\hline Sexual partner & $33(17.84)$ \\
\hline \multicolumn{2}{|l|}{ Source of acquisition } \\
\hline Pharmacy/Drug store & $51(27.57)$ \\
\hline Open market/Drug peddlers & $97(52.43)$ \\
\hline Drinking bars & $37(20.00)$ \\
\hline \multicolumn{2}{|c|}{ Perceived benefits from aphrodisiac use } \\
\hline Improved erection & $25(13.51)$ \\
\hline Prolonged sexual intercourse & $97(52.43)$ \\
\hline Gratification of sexual partner & $28(15.14)$ \\
\hline Improved performance & $35(18.92)$ \\
\hline \multicolumn{2}{|c|}{ Experienced effect from aphrodisiac use } \\
\hline Severe headache & $40(21.62)$ \\
\hline General weakness & $40(21.62)$ \\
\hline Sustained erection & $29(15.68)$ \\
\hline No effect & $76(41.08)$ \\
\hline
\end{tabular}

A multivariate logistic regression model was then used to ascertain the strength of association between selected independent variables with aphrodisiac usage. In an adjusted model (Table 4), there was a noticeable reduced but statistically significant likelihood in the usage of aphrodisiacs as the frequency level of hearing about aphrodisiac adverts reduces. Respondents who hear about aphrodisiac adverts on daily basis were 9.3 times more likely to use it compared to their counterparts who reported never hearing about it, holding all other variables constant. However, this odd reduces to about 5.8 times when the adverts were 
Table 3. Bivariate analysis of demographic and sexual characteristics on use of aphrodisiacs.

\begin{tabular}{|c|c|c|c|}
\hline \multirow[b]{2}{*}{$\begin{array}{l}\text { Variable Aphrodisiac use } \\
\qquad(\mathrm{N}=352)\end{array}$} & \multicolumn{2}{|c|}{ Aphrodisiac Use } & \multirow[b]{2}{*}{ P-value } \\
\hline & $\begin{array}{c}\text { Yes } \\
\mathrm{n}=185(\%)\end{array}$ & $\begin{array}{c}\text { No } \\
n=167(\%)\end{array}$ & \\
\hline \multicolumn{4}{|l|}{ Age group (years) } \\
\hline $18-25$ & $57(30.81)$ & $64(38.32)$ & \multirow{4}{*}{$0.031^{\star}$} \\
\hline $26-35$ & $85(45.95)$ & $83(49.70)$ & \\
\hline $36-45$ & $34(18.38)$ & $18(10.78)$ & \\
\hline $46-70$ & $9(4.86)$ & $2(1.20)$ & \\
\hline \multicolumn{4}{|l|}{ Marital Status } \\
\hline Single & $80(43.24)$ & $99(59.28)$ & \multirow{4}{*}{$<0.001^{\star}$} \\
\hline Co-habiting & $33(17.84)$ & $6(3.59)$ & \\
\hline Married & $62(33.51)$ & $58(34.73)$ & \\
\hline Divorced & $10(5.41)$ & $4(2.40)$ & \\
\hline \multicolumn{4}{|l|}{ Religion } \\
\hline Christianity & $124(67.03)$ & $119(71.26)$ & \multirow{3}{*}{$0.015^{*}$} \\
\hline Islamic & $36(19.46)$ & $40(23.95)$ & \\
\hline Traditionalist & $25(13.51)$ & $8(4.79)$ & \\
\hline \multicolumn{4}{|l|}{ Educational Level } \\
\hline No Education & $26(14.05)$ & 25 (14.97) & \multirow{4}{*}{$0.029^{*}$} \\
\hline Primary/JHS & $48(25.95)$ & $23(13.77)$ & \\
\hline SHS/Tech/Voc. & $64(34.59)$ & $62(37.13)$ & \\
\hline Tertiary & $47(25.41)$ & $57(34.13)$ & \\
\hline \multicolumn{4}{|l|}{ Occupation } \\
\hline Artisan & $31(16.76)$ & $34(20.36)$ & \multirow{6}{*}{$<0.001^{*}$} \\
\hline Civil Servant & $27(14.59)$ & $26(15.57)$ & \\
\hline Petty Trader & $52(28.11)$ & $17(10.18)$ & \\
\hline Driver & $24(12.97)$ & $12(7.19)$ & \\
\hline Others & $29(15.68)$ & $44(26.35)$ & \\
\hline Unemployed & $22(11.89)$ & $34(20.36)$ & \\
\hline \multicolumn{4}{|l|}{ Number of sex partners } \\
\hline 1 & $118(63.79)$ & $135(80.84)$ & \multirow[t]{2}{*}{$<0.001^{\star}$} \\
\hline$\geq 2$ & $67(36.21)$ & $32(19.16)$ & \\
\hline \multicolumn{4}{|l|}{ Sexual problem } \\
\hline No & $94(50.81)$ & $157(94.01)$ & \multirow[t]{2}{*}{$<0.001^{\star}$} \\
\hline Yes & $91(49.19)$ & $10(5.99)$ & \\
\hline \multicolumn{4}{|c|}{$\begin{array}{l}\text { Doctor's inquiry about sexual health } \\
\text { during routine visits }\end{array}$} \\
\hline No & $150(81.08)$ & $151(90.42)$ & \multirow[t]{2}{*}{0.003} \\
\hline Yes & $35(18.92)$ & $16(9.58)$ & \\
\hline \multicolumn{4}{|c|}{$\begin{array}{l}\text { Think doctor should routinely ask } \\
\text { about sexual function }\end{array}$} \\
\hline No & $54(29.19)$ & $57(34.13)$ & \multirow[t]{2}{*}{0.319} \\
\hline Yes & $131(70.81)$ & $110(65.87)$ & \\
\hline \multicolumn{4}{|c|}{ Frequency of adverts on aphrodisiacs } \\
\hline Never & $2(1.08)$ & $13(7.78)$ & \multirow{4}{*}{0.003} \\
\hline Everyday & $137(74.05)$ & $105(62.87)$ & \\
\hline Weekly & $24(12.97)$ & $18(10.78)$ & \\
\hline Occasionally & $22(11.89)$ & $31(18.56)$ & \\
\hline Knowledge of side effects & & & \\
\hline No & $66(35.68)$ & $13(7.78)$ & $<0.001^{*}$ \\
\hline Yes & $119(64.32)$ & $154(92.22)$ & \\
\hline
\end{tabular}

*Statistically significant effect at a $95 \%$ Confidence Interval. 
Table 4. Multiple logistic regression analysis of factors affecting aphrodisiac use.

\begin{tabular}{|c|c|c|c|c|c|c|}
\hline $\begin{array}{l}\text { Variables } \\
\mathrm{N}=352\end{array}$ & OR & $(95 \% \mathrm{CI})$ & $\mathrm{P}$-value & AOR & $(95 \% \mathrm{CI})$ & P-value \\
\hline \multicolumn{7}{|l|}{ Marital Status } \\
\hline Single $($ Ref $)$ & 1.0 & - & - & 1.0 & - & - \\
\hline Co-habiting & 6.8 & $(2.72,17.05)$ & $<0.001^{*}$ & 3.4 & $(1.11,10.59)$ & $0.031^{\star}$ \\
\hline Married & 1.3 & $(0.83,2.10)$ & 0.237 & 2.0 & $(1.09,3.57)$ & $0.025^{\star}$ \\
\hline Divorced & 3.1 & $(0.94,10.23)$ & 0.064 & 5.2 & $(1.29,21.01)$ & $0.020^{*}$ \\
\hline \multicolumn{7}{|l|}{ Educational level } \\
\hline No Education $(R e f)$ & 1.0 & - & - & 1.0 & - & - \\
\hline Primary/JHS & 2.0 & $(0.96,4.21)$ & 0.065 & 0.6 & $(0.23,1.52)$ & 0.282 \\
\hline SHS & 1.0 & $(0.52,1.90)$ & 0.982 & 0.5 & $(0.21,1.06)$ & 0.069 \\
\hline Tertiary & 0.8 & $(0.41,1.55)$ & 0.498 & 0.3 & $(0.14,0.79)$ & $0.013^{*}$ \\
\hline \multicolumn{7}{|c|}{ Number of sexual partners } \\
\hline $1($ Ref $)$ & 1.0 & - & - & 1.0 & - & - \\
\hline$\geq 2$ & 2.4 & $(1.47,3.90)$ & $<0.001^{*}$ & 2.4 & $(1.28,4.34)$ & $0.006^{*}$ \\
\hline \multicolumn{7}{|l|}{ Sexual problem } \\
\hline No $(R e f)$ & 1.0 & - & - & 1.0 & - & - \\
\hline Yes & 15.2 & $(7.5,30.64)$ & $<0.001^{\star}$ & 14.4 & $(6.58,31.37)$ & $<0.001^{*}$ \\
\hline \multicolumn{7}{|l|}{ Chronic health problem } \\
\hline No $(\operatorname{Ref})$ & 1.0 & - & - & 1.0 & - & - \\
\hline Yes & 2.0 & $(1.11,3.50)$ & $0.02^{*}$ & 0.7 & $(0.31,1.53)$ & 0.364 \\
\hline \multicolumn{7}{|l|}{ Frequency of adverts } \\
\hline Never $($ Ref $)$ & 1.0 & - & - & 1.0 & - & - \\
\hline Everyday & 8.5 & $(1.87,38.40)$ & $0.006^{*}$ & 9.3 & $(1.68,51.51)$ & $0.011^{\star}$ \\
\hline Weekly & 8.7 & $(1.73,43.32)$ & $0.009^{*}$ & 8.4 & $(1.32,53.62)$ & $0.024^{\star}$ \\
\hline Occasionally & 4.6 & $(0.94,22.52)$ & 0.059 & 5.8 & $(0.94,36.06)$ & 0.057 \\
\hline \multicolumn{7}{|l|}{ Knowledge of side effects } \\
\hline No $(R e f)$ & 1.0 & - & - & 1.0 & - & - \\
\hline Yes & 0.2 & $(0.08,0.29)$ & $<0.001^{*}$ & 0.2 & $(0.07,0.33)$ & $<0.001^{*}$ \\
\hline
\end{tabular}

*Statistically significant effect at a $95 \%$ Confidence Interval.

heard occasionally. Very similar observations were made regarding the level of reported educational level attained at the time of the study on usage. Thus, the likelihood of usage of aphrodisiacs turns to progressively reduce from 0.6 to 0.3 , as the level of education increases. The higher the level of education the less likely the usage. Making education a protective factor to the usage of the aphrodisiacs. On the other hand, it was observed from the data that study participants with two (2) or more sexual partners and those who reported having sexual problems were 2.4 and 14.4 times more likely to use aphrodisiacs when other covariates were adjusted for compared to those with single partners and those without sexual problems respectively. Individuals co-habiting at the time of the study where 3.4 times more likely to also use the aphrodisiacs when compared to their single counterparts holding other variables constant. Reported knowledge on associated side effects of usage turns to have a protective effect as respondents who have some level of knowledge on the harms were predicted to be 0.8 times less likely to use the drug compared to their counterparts who admitted having no knowledge. 


\section{Discussion}

The current study revealed that demographic factors: age, marital status, educational level, occupation, and religion were significantly associated with the use of aphrodisiacs. It was observed that individuals who were cohabiting at the time of the study were 3.4 times more likely to use aphrodisiacs compared to their single counterparts holding all other variables constant. The study again found that the odds of an individual using an aphrodisiac decreased with higher educational attainment. A probable reflection that, the educated men are more likely to access and understand information regarding the possible side-effects from the use of these drugs, hence the low usage rate. This finding, however, contradicts a study in Saudi Arabia which indicated that there is high consumption of sex enhancing medications among highly educated males compared to those with a lower educational attainment [16]. This difference could be attributed to the difference in study settings and the difference in access to information on aphrodisiacs where the study was conducted. Almost all the respondents (95.7\%) admitted having some knowledge of aphrodisiacs generally. This study found that one-hundred and eighty-five (52.6\%) of the respondents had ever used aphrodisiacs and amongst them, more than half (58\%) were using these drugs at the time of the study. Similar information was provided in a study investigating the indiscriminate use of sex enhancing products among Ghanaians, where $61 \%$ of males were found to be using these drugs [15]. A lower prevalence (26\%) was, however, reported by Makwana et al., (2013) in an online based survey [16]. A similar trend of high usage has been reported by Ahmed et al., (2017) which found that most $(67.2 \%)$ of sex enhancing medication users were aged $\leq 45$ years. It is, therefore, suggestive that the use of aphrodisiac is high among youthful populations which is a public health concern. These individuals often use the drugs when there is no diagnosed disease but just to enhance their sexual prowess without due cognizance of the health implications from chronic usage. A further probe into the source and nature of the aphrodisiacs used revealed about $72.4 \%$ of these substances were obtained from the open markets and drinking bars [16]. It is important to note that $24.2 \%$ of the aphrodisiac users were consuming herbal aphrodisiacs with an alcohol base. This corroborates a study by Tabil, (2015) in Ghana which showed that $63.9 \%$ of the studied population was consuming alcoholic beverages mixed with aphrodisiacs [10]. The proliferation of herbal aphrodisiac with alcohol base in the Ghanaian market is alarming and many of these have high alcohol concentrations. Studies by Arackal and Benegal, (2007) in India showed that sexual dysfunction particularly, premature ejaculation is common in subjects with alcohol dependence [17]. This implies many of the populace who are taking these alcoholic beverages with the aim of improving their sexual performance may only end up worsening their situation and suffer the harmful effects that come with the chronic use of aphrodisiacs. Most of the users reportedly procure aphrodisiacs with recommendations from peers and acquaintances, with only $3.2 \%$ consulting health professionals. This shows that 
many of the users are taking these drugs without any medical direction. This finding is similar to another study done in Ghana which revealed that friends and family played a vital role in a man's decision to use aphrodisiacs [11]. The sexual characteristics of an individual play a crucial role in the use of aphrodisiac. The more sexual partners one has, the more likely it is that the individual will use an aphrodisiac. Makwana et al., (2013) reported that 69\% of aphrodisiacs users had more than one sexual partner and in 2017 [18], Ahmed et al., also found that sex-enhancing medications users had more than one sexual partner [16]. These findings are not different from what this present study found as the bivariate analysis demonstrated a statistically significant association between the number of sexual partners and aphrodisiac use. Individuals with two or more partners at the time of the study were 2.4 times more likely to use aphrodisiacs $(\mathrm{AOR}=2.4,95 \% \mathrm{CI} 1.28-4.34)$ compared with respondents with only one sexual partner after controlling for all confounders. From the bivariate analysis, it was clear that the presence of sexual problems influences the use of aphrodisiac and this association was further confirmed in the multivariate analysis as those with sexual problems had about 14 times likelihood of using aphrodisiacs (AOR $=14.4,95 \%$ CI 6.58 - 31.37) compared to those who reported no sexual problems after adjusting for the other predicting variables. The influence of advertisements, chronic health conditions and participant's knowledge of side effects were analyzed in the multiple logistic regression. From the results, it was discovered that respondents who heard about aphrodisiac adverts on daily basis were 9.3 times more likely to use it compare to their counterparts who reported never hearing about it, holding all other variables constant. The odds further decreased 5.8 times among those who heard these advertisements occasionally. This findings, therefore, suggests that advertisement plays a crucial role in the use of aphrodisiacs. The sources of these advertisements were the media (radio, television, and internet), markets places and billboards with the media being the most common source of these advertisements. Respondent's knowledge of side effects from use of aphrodisiacs also demonstrated a statistically significant association implying that subjects who had knowledge of side effects were less likely to use aphrodisiacs compared with those without knowledge of side effects. Our study found the likelihood of using aphrodisiac increases with lower educational attainment as such it can be deduced that educated people have more access to information from different sources like schools, newspapers, internet among others hence their knowledge of side effects which will result in their low use of aphrodisiacs.

\section{Conclusion}

Usage was found to be higher among those with lower educational attainment. Advertisement was also discovered to significantly influence the use of aphrodisiacs as those who hear or watch these advertisements on a daily basis were more likely to use these drugs compared to those who never heard about them. Other 
factors such as the number of sexual partners, the presence of sexual problems and knowledge of side effects independently predicted the use of aphrodisiacs. Chronic health conditions were not found to be associated with the use of aphrodisiac after adjusting for possible confounders. The benefits users claimed to have experienced from usage were more recreational and generally, it was perceived that the main reason for use of aphrodisiacs was to achieve prolonged sexual intercourse. The major source of acquiring aphrodisiacs was from the open markets based on recommendations from friends and family. The level of education attained and also the amount of knowledge on the accompanying side effects of using aphrodisiacs were predicted to have a protective effect to usage, thereby making public health education the best route to fighting this menace in the Ghanaian society and beyond.

\section{Limitations}

Despite the contribution of this study to scientific knowledge, it cannot go without mention that information gathered from the respondents could be subjected to sampling and recall biases given the sampling technique adapted and the fact that some of the information was self-reported. Further comprehensive qualitative research work could be done as a follow-up study.

\section{Authors' Contributions}

This work was carried out in collaboration between all authors. PAM and SM participated in conceiving the study and in the development of data collection tools. PAM carried out data collection. SM, PAM and GKA participated in the data analysis and drafting of the manuscript. All authors read and approved of the final manuscript.

\section{Conflicts of Interest}

All authors declare no conflict of interest.

\section{References}

[1] Polomeno, V. (1999) Sex and Babies: Pregnant Couples' Postnatal Sexual Concerns. The Journal of Perinatal Education, 8, 9-18. https://doi.org/10.1624/105812499X87312

[2] Ramlachan, P. and Campbell, M.M. (2014) Male sexual Dysfunction. South African Medical Journal, 104, 447. https://doi.org/10.7196/SAMJ.8376

[3] Porst, H. (2004) Phosphodiesterase Type-5 Inhibitors: A Critical Comparative Analysis. EAU Update Series, 2, 56-63. https://doi.org/10.1016/j.euus.2004.03.007

[4] Patwardhan, B., Mutalik, G. and Tillu, G. (2015) Drug Discovery and Ayurveda. Integrative Approaches for Health, 6, 229-258. https://doi.org/10.1016/B978-0-12-801282-6.00009-7

[5] Ali, J., Ansari, S. and Kotta, S. (2013) Exploring Scientifically Proven Herbal Aphrodisiacs. Pharmacognosy Reviews, 7, 1. https://doi.org/10.4103/0973-7847.112832

[6] Bhagavathula, A.S., Elnour, A.A. and Shehab, A. (2016) Pharmacovigilance on Sex- 
ual Enhancing Herbal Supplements. Saudi Pharmaceutical Journal, 24, 115-118. https://doi.org/10.1016/j.jsps.2015.01.018

[7] Ghanaweb (2016) Use of Aphrodisiacs Killing Ghanaians. Accra.

[8] Amidu, N., Owiredu, W.K.B., Woode, E., Addai-Mensah, O., Gyasi-Sarpong, K.C. and Alhassan, A. (2010) Prevalence of Male Sexual Dysfunction among Ghanaian Populace: Myth or Reality. International Journal of Impotence Research, 22, 337-342. https://doi.org/10.1038/ijir.2010.24

[9] Camacho, M.E. and Reyes-Ortiz, C.A. (2005) Sexual Dysfunction in the Elderly: Age or Disease? International Journal of Impotence Research, 17, S52-S56. https://doi.org/10.1038/sj.ijir.3901429

[10] Tabil, E. (2016) Consumption of Alcoholic Beverages Mixed with Aphrodisiacs in the Okaikoi Sub-Metropolis. University of Ghana, Accra.

[11] Atindanbila, S., Asafo, M.S., Attiogbe, A., Abasimi, E. and Amooba, P. (2014) Bio-Psychosocial Factors Associated with the Use of Sexual Enhancers among Ghanaian Men. International Journal of Research-Granthaalayah, 2, 20-37.

[12] Skalicka-Woźniak, K., Georgiev, M.I. and Orhan, I.E. (2017) Adulteration of Herbal Sexual Enhancers and Slimmers: The Wish for Better Sexual Well-Being and Perfect Body Can Be Risky. Food and Chemical Toxicology, 108, 355-364. https://doi.org/10.1016/j.fct.2016.06.018

[13] Ocloo, D.R. (2015) FDA Bans 6 Aphrodisiacs; They Contain False Sex Enhancing Ingredients. Daily Graphi.

https://www.graphic.com.gh/news/general-news/fda-bans-6-aphrodisiacs-they-cont ain-false-sex-enhancing-ingredients.html

[14] Ghana Statistical Service (2012) 2010 Population and Housing Census. Ghana Statistical Service, 1-117.

[15] Danquah, C.A., Koffuor, G.A., Anto, B.P. and Nimako, K.A. (2011) The Indiscriminate Use of Sex Enhancing Products among Ghanaians: Prevalence, and Potential Risk. Advances in Applied Science Research, 2, 350-359.

[16] Ahmed, A.F., Alshahrani, S., Morgan, A., Gabr, A.H., Abdel-Razik, M. and Daoud, A. (2017) Demographics and Sexual Characteristics of Sex-Enhancing Medication Users: Study of a Web-Based Cross-Sectional Sample of Sexually Active Men. Arab Journal of Urology, 15, 366-371. https://doi.org/10.1016/j.aju.2017.09.003

[17] Benegal, V. and Arackal, B. (2007) Prevalence of Sexual Dysfunction in Male Subjects with Alcohol Dependence. Indian Journal of Psychiatry, 49, 109. https://doi.org/10.4103/0019-5545.33257

[18] Makwana, S., Solanki, M., Raloti, S. and Dikshit, R. (2013) Evaluation of Recreational Use of Aphrodisiac Drugs and Its Consequences: An Online Questionnaire Based Study. International Journal of Research in Medical, 2, 51-59. 